\title{
The effect of intertrial interval on avoidance learning in fish'
}

The effect of intertrial interval on the acquisition of a shuttlebox avoidance response in fish, Xiphophorus helleri, was studied over five days of 20 trials each with intertrial intervals of $.5,1,2,5,10$, and 20 minutes. The results supported the hypothesis that leaming is facilitated by longer intertrial intervals, but the U-shaped function generally obtained with rats was not evident within the limits of the time intervals employed in this experiment.

Several theoretical interpretations of avoidance learning suggest that the instrumental avoidance response is reinforced by the reduction of conditioned fear, which is assumed to occur during the time interval between the response and the onset of the CS on the following trial. The length of this intertrial interval (ITI) should, therefore, have a direct relationship to the speed of acquisition of the avoidance response.

Data available on the effect of ITI on acquisition of an avoidance response vary with the type of response required. Murphy \& Miller (1956), Levine \& England (1960), and Brush (1962) have all reported better performance by rats at longer ITIs in the shuttlebox. The ITIs varied from $20 \mathrm{sec}$. in the Levine and England study to $20 \mathrm{~min}$. in the Brush experiment.

Pearl (1963), as well as Pearl \& Fitzgerald (1966), have shown, on the other hand, that the learning of a discriminated lever press avoidance response by rats is facilitated by shorter ITIs.

The purpose of the present experiment was two-fold: first, to study the effect of ITI on the acquisition of a shuttlebox avoidance response in fish, and, second, to compare the effect of the ITI on fish with the data available on the rat.

\section{Subjects}

The Ss for this study were 79 experimentally naive Mexican Swordtails, Xiphophorus helleri. They were obtained locally and housed for several weeks prior to the experiment in 20 gallon community tanks. Apparatus

The aquatic shuttlebox used in this study was built from an 18 in. Betta splendens display tank enclosed in a plywood housing. The tank was divided into two compartments of equal size by a gray Plexiglas doorway. The CS was the onset of a $25 \mathrm{w}$ light at the end of the compartment occupied by $S$ at the beginning of each trial. The US was an electric shock delivered through a pair of electrodes set in the ends of the tank. The shock was developed from a $110 \mathrm{v}$ ac source, passed through a variable resistor, and pulsed by a shock interrupter. The shock level was the lowest voltage required to bring about consistent escapes by pilot Ss. The onset and duration of the CS and US were controlled by a pair of Hunter interval timers connected in series, and a Standard Electric timer was used to measure latencies to the nearest .01 sec. Six identical shuttleboxes were used throughout this study.

Procedure

The fish were randomly assigned to six ITI groups and placed in individual tanks which were heated and continuously aerated. Each S was given a $30 \mathrm{~min}$. adaptation period in the shuttlebox on each of two days preceding training. The first day of training consisted of 10 trials during which only the CS was presented. The light followed $S$ from compartment to compartment for 20 sec. per trial. Ss were dropped from the study if they avoided the CS alone on more than five of the 10 trials, or on more than two of the last five trials. Seven Ss were eliminated for this reason. This was followed by five days of avoidance conditioning with 20 trials being given per day. A delayed conditioning procedure was used, with a $15 \mathrm{sec}$. CS-US interval and a $5 \mathrm{sec}$. shock duration. A response to the CS alone terminated the light and allowed $S$ to avoid the shock completely, while a response during the $5 \mathrm{sec}$. shock period terminated both the CS and the US. Both the CS and US were terminated automatically at the end of $20 \mathrm{sec}$. on those trials where $\mathrm{S}$ failed to make the shuttle response. One-sixth of the Ss were trained with each of six ITIs: $.5,1,2,5,10$, and $20 \mathrm{~min} .$, measured from the onset of the CS on one trial to the onset of the CS on the next trial.

\section{Results}

The mean number of avoidance responses for each session, as well as mean latencies of these responses, as a function of intertrial interval are shown in Fig. 1. Analysis of variance of the number of avoidances over days indicated that the main effects of ITI and days were significant at the .001 level of confidence, as was the interaction $(F=5.89, \mathrm{df}=5 / 64 ; \mathrm{F}=53.55, \mathrm{df}=4 / 256$; $\mathrm{F}=2.71$, df $=20 / 256$ ).

Analysis of variance was also applied to the latencies of the avoidance responses. The main effects of ITI and days were both significant at the .001 level of confidence $(F=4.89, \mathrm{df}=5 / 64 ; \mathrm{F}=8.00, \mathrm{df}=4 / 256)$. The interaction was significant at the .01 level $(F=2.36$, $\mathrm{df}=20 / 256$ ).

\section{Discussion}

The results of this experiment parallel, to a considerable extent, those obtained by Brush (1962) with the 


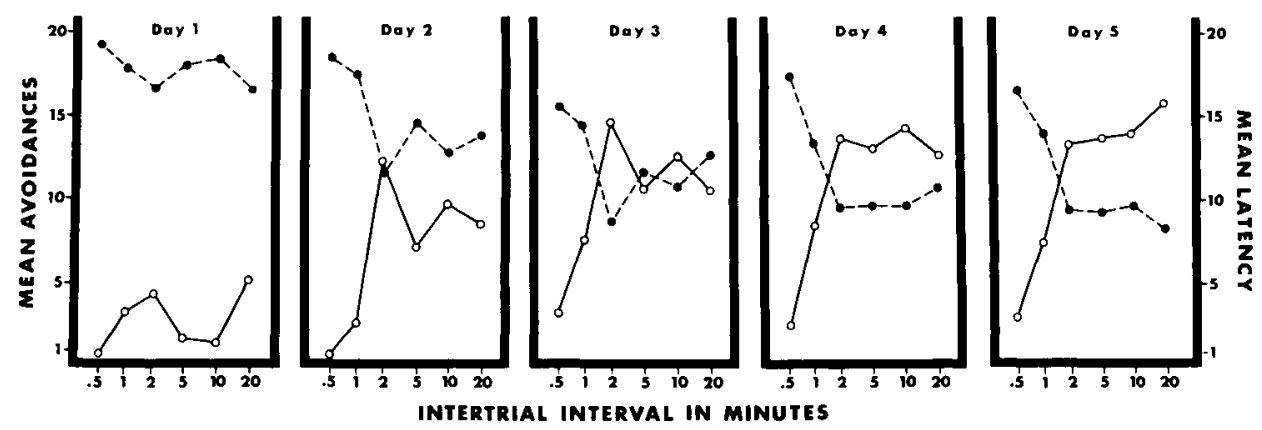

Fig. 1. Mean number of avoidances $(0-0)$ and mean latencies (o--- - o) for the avoidances as a function of the intertrial interval for each day of the experiment.

hooded rat. This would seem to support the hypothesis that the reduction of conditioned fear during the interval between the termination of the CS on one trial and the onset of the $C S$ on the next trial serves as a reinforcer in avoidance conditioning, especially during the early stages of learning. These data differ, however, from those of Brush in that the expected U-shaped function was not evident. Brush found that the mean number of avoidances increased with intertrial interval from $.5 \mathrm{~min}$. to $5 \mathrm{~min}$., but then decreased from there to 10 and $20 \mathrm{~min}$. In the present study the decrement at the longer ITIs did not appear. On the fifth day, for example, the $\mathrm{U}$-shaped function was most pronounced in the Brush study. In the present study, the mean number of avoidances made by the six groups were $3.00,7.62$, $13.27,13.82,13.92$, and 16.00 in order of increasing ITI. The $20 \mathrm{~min}$. group showed steady improvement over the five days of the experiment. They averaged $5.09,8.27,10.64,12.73$, and 16.00 avoidances on days one through five, respectively. The mean of 16 avoidances on day five was the best performance by any group on any day of the experiment.

It may very well be that ITIs longer than those employed in this study would yield data similar to those of Brush. If his tentative explanation that the decrement in performance at longer ITIs is due to the extinction of that portion of the fear which has been conditioned to apparatus cues is correct, this difference might be explained by the fact that fish seem to be much more responsive to changes in their environment than rats. Thus, apparatus cues, and the subsequent fear associated with them, might be more persistent and require longer ITIs for extinction to occur.

The disparity between the results of shuttlebox studies and the work on lever press avoidance learning merits further consideration. Certainly one would expect the effects of ITI to be nearly the same regardless of the operant involved. Yet, the results of the lever press work are consistently disparate with the results of studies employing the shuttlebox. Pearl \& Fitzgerald (1966), for example, trained four groups of rats with ITIs of $.2,1,5$, and 30 sec., and found that the performance of their Ss was inversely related to the length of the ITI. In fact, they reported that the rats in the .2 sec. group avoided on $70 \%$ of the trials on the first day of the experiment, while the $30 \mathrm{sec}$. group avoided on only slightly more than $20 \%$ of the trials. Similar results were reported by Pearl (1963).

The disparity in results may be due, in part at least, to the nature of the response which develops in these two situations. In the shuttlebox experiments, the response consists of a more discrete operant (i.e.,jumping over a hurdle), while in the lever press studies the response may consist of a burst of presses. This burst or perseveration of pressing often follows the shock, rather than preceding it, and, if the ITI is short enough, may persist until the next trial. In such a case, the shock on the next trial is avoided. In support of this, Pearl (1963) and Ulrich, Holz, \& Azrin (1964) report higher rates of responding at shorter ITIs. These lever press studies employing such short ITIs may really involve something other than discriminated avoidance learning. The CS serves little purpose when S's perseveration of response to one shock is reinforced by the avoidance of the shock on the next trial. This places the behavior more in the class of escape learning, or even free operant avoidance.

\section{References}

Brush, F. R. The effects of intertrial interval on avoidance learning in the rat. J. comp. physiol. Psychol., 1962, 55, 888-892.

Levine, S., \& England, S. J. Temporal factors in avoidance conditioning. J. comp. physiol. Psychol., 1960, 53, 282-283.

Murphy, J. V., \& Miller, R. E. Spaced and massed practice with a methodological consideration of avoidance conditioning. $J$. exp. Psychol., 1956, 52, 77-81.

Pear, J. Intertrial interval and acquisition of a lever press avoidance response. J. comp. physiol. Psychol., 1963, 56, 710-712.

Pear, J., \& Fitzgerald, J. J. Better discriminated bar-press avoidance at short intertrial intervals. Psychon. Sci., 1966, 4, 41-42.

Ulrich, R. E., Holz, W. C., \& Azrin, N. H. Stimulus control of avoidance behavior. J. exp. Anal. Behav., 1964, 7, 129-133.

\section{Note}

1. This study was supported by Grant 22-11-A from the Research Foundation of State University of New York. 